\title{
Can we make a placenta in the Petri dish?
}

\author{
Ramiro Alberio and Kevin D Sinclair \\ School of Biosciences, University of Nottingham, Loughborough LE12 5RD, UK \\ Correspondence should be addressed to R Alberio; Email: Ramiro.Alberio@nottingham.ac.uk
}

Reproduction (2014) 147 E3

In this issue, we introduce what we hope will become a series of highly topical and, in some instances, controversial debate articles. Our idea is to promote constructive discussion of arguments both 'for' and 'against' particular research concepts, and so foster and direct future research endeavors that will shed light into new and exciting areas of reproductive biology.

The first Debate in this series could not be more appropriate, as it deals with the highly controversial topic of differentiation of human embryonic stem cells (hESC) into trophoblast cells. The contributors, led by $\mathrm{R}$ Michael Roberts and Roger Pedersen, are the leading researchers in this field. In this issue they present a detailed account of the evidence both for and against this biological concept (Roberts et al. 2014). There is great interest in both the scientific and medical communities in determining whether hESC can differentiate into a functional trophoblast, as this may lead to the development of in vitro models of placentation. In turn, this could be used to improve our understanding of placental dysfunctions such as pre-eclampsia (Ezashi et al. 2012). However, it is important to establish whether such in vitro models are genuine functional equivalents to embryonic tissues. The availability of embryo-derived pluripotent stem cells provides exciting new opportunities for driving the differentiation of cells into specific lineages, although it is recognized that these opportunities can only be fully realized when a detailed understanding of the in vitro differentiation process is known. It would appear from this Debate that complementary investigations using in vitro and in vivo functional experiments will be needed for settling differences in the arguments presented; and only time will tell whether trophoblast differentiation can be effectively modeled in a Petri dish.

\section{References}

Ezashi T, Telugu BP \& Roberts RM 2012 Model systems for studying trophoblast differentiation from human pluripotent stem cells. Cell and Tissue Research 349 809-824. (doi:10.1007/s00441-012-1371-2)

Roberts RM, Loh KM, Amita M, Bernardo AS, Adachi K, Alexenko AP, Schust DJ, Schulz LC, Telugu BPVL, Ezashi T et al. 2014 Differentiation of trophoblast cells from human embryonic stem cells: to be or not to be? Reproduction 147 D1-D12. (doi:10.1530/REP-14-0080) 